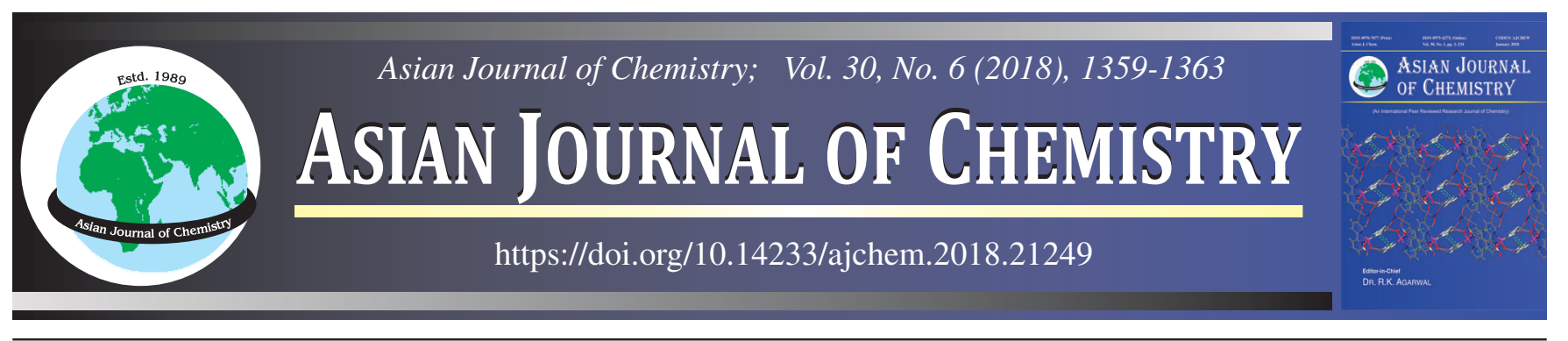

\title{
Synthesis, Spectral Characterization and in vitro Antidiabetic Properties of Oxovanadium(IV) Complexes with 2-\{(E)-Pyridin-4-yl[2-(pyridin-2-yl)hydrazinylidene]methyl $\}$ pyridine
}

\author{
Babbu Lal Patel ${ }^{1, *}$, Yogendra Pratap Singh ${ }^{2}$, R.N. Patel ${ }^{2}$ and P.K. Singh ${ }^{1}$
}

${ }^{1}$ Department of Chemistry, S.G.S. Government P. G. College, Sidhi-486 661, India

${ }^{2}$ Department of Chemistry, A.P.S. University, Rewa-486 003, India

*Corresponding author: E-mail: babbulalpatel@gmail.com

Received: 24 January 2018;

Accepted: 28 February 2018;

Published online: 30 April 2018;

AJC-18894

\begin{abstract}
A series of oxovanadium(IV) complexes $[\mathrm{VO}($ phen $)(\mathrm{L})]\left(\mathrm{NO}_{3}\right)_{2}(\mathbf{1}),[\mathrm{VO}(\operatorname{dimphen})(\mathrm{L})]\left(\mathrm{NO}_{3}\right)_{2}(\mathbf{2}),[\mathrm{VO}(\mathrm{bpy})(\mathrm{L})](\mathrm{NO})_{2}(\mathbf{3})$ and $\left[\mathrm{VO}(\right.$ bpybenImH) $(\mathrm{L})]\left(\mathrm{NO}_{3}\right)_{2}(4)$ with mixed ligands, a tridentate N,N,N-donor Schiff base ligand [viz., 2- $\{(E)$-pyridin-4-yl[2-(pyridin-2yl)hydrazinylidene]methyl \}pyridine] (L) and a bidentate N,N ligand [viz., 1,10-phenanthroline (phen), 4,7-dimethyl-1,10-phenanthroline (dimphen), 2,2'-bipyridyl (bpy) and 2-(2-pyridyl)benimidazole (bipybenImH)], have been synthesized and characterized by elemental analysis, UV-visible spectroscopy, Fourier transform IR spectroscopy, EPR spectroscopy, cyclic voltammetric and differential pulse voltammetric techniques. The oxidation state of V(IV) with $d^{1}$ configuration was confirmed by EPR spectroscopy. The complexes were also tested for in vitro antidiabetic activity. Moderate $\alpha$-glucosidase inhibitions are shown by these complexes. This suggested that the complexes may be promising candidates as antidiabetic agents.
\end{abstract}

Keywords: Oxovanadium(IV) complexes, UV-visible, Electrochemistry, Anti-diabetic activity.

\section{INTRODUCTION}

Oxovanadium(IV) complexes are of current interest due to their importance in the study of biochemical and pharmacological properties [1]. Many vanadium complexes provide a suitable structural and functional model for these enzymes [2]. Intensive studies carried out over the last two decades [3] showed that vanadium is one of the most important supplements for oral diabetes therapy [4]. Inorganic vanadium salts are poorly absorbed from the digestive system, thus high oral doses are required. Coordination complexes of vanadium are current candidate insulin enhancing compounds and can be tailored to optimize the desired properties for a drug. Insulin, a pancreatic signalling hormone, is the principal treatment for type 1 diabetes and is often required for type 2 diabetes as well. Insulin is not orally active and must be administered via intramuscular injection. To clarify its biological role, it is of primary importance to understand the mechanisms of reaction and complexation of vanadium in organisms and to find the target biomolecules [5,6]. Among the biomolecules present in intra and extra-cellular fluids, proteins have a special importance because of their high amount in the cellular environment and their possible interaction with metal ions through a number of active sites. Several oxovanadium(IV) complexes with various coordination modes [7] and the relationship between their structures and insulin-mimetic activities has been already examined by several research groups [8] evaluating both in vivo and in vitro results.

At present, the synthesis of oxovanadium(IV) and Schiff bases (2-\{(E)-pyridin-4-yl[2-(pyridin-2-yl)hydrazinylidene]methyl pyridine) with polypyridyl ligands has become a popular topic of research. Schiff base may act as tridentate ligands forming stable complexes with many metallic ions and in particular, asymmetric tridentate Schiff bases may give rise to low molecular weight complexes of great interest in the modern synthetic inorganic chemistry. Oxovanadium(IV) coordination complexes may appear as an attractive source for model systems in the study of low dimensional complexes [9]. 1,10-Phenanthroline (phen), 4,7-dimethyl-1,10-phenanthroline (dimphen), 2,2'-bipyridyl (bpy) and 2-(2-pyridyl)benimidazole (bipybenImH) chelators (polypyridyl ligands) act as potential antitumor agents $[10,11]$. These polypyridyl ligands act as bidentate planar chelate ligands, coordinating through the two imine nitrogen atoms. They have been extensively used as ligands in the formation of coordination compounds as modelling agents.

In our previous works, we have synthesized and characterized vanadium(IV)/(V) complexes with tridentate Schiff base ligands [12-14]. To continue our research, we have synthesized and characterized vanadium(IV) complexes. Biological testing of the insulin enhancing behaviour of these new vanadium(IV) complexes have also been carried out. 


\section{EXPERIMENTAL}

All the solvents were purchased from standard commercial sources and used as received. $\mathrm{VOSO}_{4} \cdot 5 \mathrm{H}_{2} \mathrm{O}$ (Fisher), $\mathrm{NaNO}_{3}$ (E. Merck, India), 1,10-phenanthroline (Fisher), 4,7-dimethyl1,10-phenanthroline (Acros), 2-(2-pyridyl)benimidazole (Acros), 2-benzoylpyridine (Acros) and 2-hydrazinopyridine (Acros) were used as received.

Microanalyses on carbon, hydrogen and nitrogen were performed using the Euro-E 3000 elemental analyzer. Solid samples for IR spectroscopy were compressed as KBr pellets and the IR spectra were recorded on a Bruker $\alpha$-T spectrophotometer at normal temperature in the range of 4000 to $400 \mathrm{~cm}^{-1}$. Electronic absorption spectra were measured with Shimadzu UV-visible recording spectrophotometer UV-1601 at room temperature in solution. The electrochemistry of the complexes 1-4 $\left(3 \times 10^{-3} \mathrm{M}\right)$ in $\mathrm{CH}_{3} \mathrm{OH}$ containing $0.1 \mathrm{M}$ tetrabutyl ammonium perchlorate (TBAP) as supporting electrolyte was determined at room temperature by cyclic voltammetry $(\mathrm{CV})$ and differential pulse voltammetry (DPV) using a three-electrode system under deaerated conditions and a BAS-100 electrochemical analyzer. A glassy-carbon and platinum wire was used as the working electrode and the counter electrode, respectively. The reversibility of the electrochemical process was evaluated by standard procedures and all potentials were recorded against $\mathrm{Ag} / \mathrm{AgCl}$ reference electrode. All measurements were carried out at $298 \mathrm{~K}$ under nitrogen. All solutions were purged with nitrogen gas prior to measurements. Electron paramagnetic resonance (EPR) spectra were recorded with a Varian E-line Century Series EPR spectrometer equipped with a dual cavity and operating at the $\mathrm{X}$-band of the $100 \mathrm{kHz}$ modulation frequency. Tetracyanoethylene (TCNE) was used as a field marker $(g=2.00277)$. The molar ion-exchange was measured using a Systronics digital conductivity meter (TDS-308) using a $3 \times 10^{-3} \mathrm{M}$ solution in $\mathrm{CH}_{3} \mathrm{OH}$.

Synthesis of Schiff base: Schiff base (2- $\{(E)$-pyridin-4yl[2-(pyridin-2-yl)hydrazinylidene]methyl $\}$ pyridine) (L) was synthesized by adopting the procedure reported in the literature [15]. A solution of pyridin-2-yl(pyridin-4-yl)methanone $(0.920$ $\mathrm{g}, 5.0 \mathrm{mmol})$ in methanol $(10 \mathrm{~mL})$ was added to a solution of 2-hydrazinopyridine $(0.545 \mathrm{~g}, 5.0 \mathrm{mmol})$ in methanol $(10 \mathrm{~mL})$ and the resulting reaction mixture was refluxed with constant stirring for $4 \mathrm{~h}$ and then filtered to remove the insoluble part, if any. It was kept at room temperature when coloured crystals of Schiff base separated out from their solutions. The pale yellow crystals thus obtained were washed with ethanol and dried in $\mathrm{CaCl}_{2}$ desiccators. Yield: $76 \%$. Elemental analysis: Calcd. (found) (\%) for $\mathrm{C}_{16} \mathrm{H}_{13} \mathrm{~N}_{5}$ : C, 69.80 (69.76); H, 4.76 (4.65); N, 25.44 (25.39).

Synthesis of $[\mathrm{VO}($ phen $)(\mathrm{L})]\left(\mathrm{NO}_{3}\right)_{2}(\mathbf{1})$ : To a methanolic solution $(10 \mathrm{~mL})$ of 1,10 -phenanthroline $(0.180 \mathrm{~g} 1.0 \mathrm{mmol})$ was added dropwise $\mathrm{VOSO}_{4} \cdot 5 \mathrm{H}_{2} \mathrm{O}(0.156 \mathrm{~g}, 1.0 \mathrm{mmol})$ in water $(5 \mathrm{~mL})$. The resulting solution was stirred for $20 \mathrm{~min}$ and then added dropwise to a methanol solution of Schiff base $(2-\{(E)-$ pyridin-4-yl[2-(pyridin-2-yl)hydrazinylidene]methyl $\}$ pyridine) $(\mathbf{L})(0.274 \mathrm{~g}, 1.0 \mathrm{mmol})$. In the resulting reaction mixture, sodium nitrate $(0.168 \mathrm{~g}, 2.0 \mathrm{mmol})$ was added and again allowed to stir for $1 \mathrm{~h}$ at room temperature resulted in the precipitation of a burgundy solid which was filtered off, washed with methanol and dried over fused $\mathrm{CaCl}_{2}$. Yield: $51 \%$. Elemental analysis: Calcd. (found) $(\%)$ for $\mathrm{C}_{29} \mathrm{H}_{22} \mathrm{~N}_{8} \mathrm{O}_{7} \mathrm{~V}: \mathrm{C}, 53.96$ (53.92); H, 3.43 (3.40); N, 17.35 (17.32). Molar conductivity $\left(\mathrm{CH}_{3} \mathrm{OH}\right): \lambda_{\mathrm{M}}=210 \Omega^{-1} \mathrm{~cm}^{2} \mathrm{M}^{-1}$. The solid state magnetic moment $\left(\mu_{\text {eff }}\right)$ was found to be 1.74 B.M.

Synthesis of [VO(dimphen)(L)](NO$\left.)_{3}\right)_{2}(2)$ : This complex was synthesized by a similar method of complex $\mathbf{1}$ by using 2,7-dimethyl-1,10-phenanthroline instead of 1,10-phenanthroline. Yield: $48 \%$. Elemental analysis: Calcd. (found) (\%) for $\mathrm{C}_{31} \mathrm{H}_{26} \mathrm{~N}_{8} \mathrm{O}_{7} \mathrm{~V}$ : C, 55.28 (55.24); H, 3.89 (3.83); N, 16.63 (16.61). Molar conductivity $\left(\mathrm{CH}_{3} \mathrm{OH}\right): \lambda_{\mathrm{M}}=213 \Omega^{-1} \mathrm{~cm}^{2} \mathrm{M}^{-1}$. The solid state magnetic moment $\left(\mu_{\text {eff }}\right)$ was found to be 1.76 B.M.

Synthesis of [ $\mathbf{V O}(\mathbf{b p y})(\mathbf{L})]\left(\mathbf{N O}_{3}\right)_{2}(3)$ : This complex was synthesized following the same general procedures as those described for complex 1, with 2,2'-bipyridyl in place of 1,10phenanthroline. Yield: $47 \%$. Elemental analysis: Calcd. (found) (\%) for $\mathrm{C}_{27} \mathrm{H}_{22} \mathrm{~N}_{8} \mathrm{O}_{7} \mathrm{~V}$ : C, 52.18 (52.15); H, 3.52 (3.56); N, 18.03 (18.01). Molar conductivity $\left(\mathrm{CH}_{3} \mathrm{OH}\right): \lambda_{\mathrm{M}}=209 \Omega^{-1} \mathrm{~cm}^{2} \mathrm{M}^{-1}$. The solid state magnetic moment $\left(\mu_{\text {eff }}\right)$ was found to be 1.75 B.M.

Synthesis of $[\mathrm{VO}($ bpyben $\mathrm{ImH})(\mathrm{L})]\left(\mathrm{NO}_{3}\right)_{2}$ (4): This complex was synthesized following the same general procedures as those described for complex 1, with 2-(2-pyridyl)benimidazole in place of 1,10-phenanthroline. Yield: $45 \%$. Elemental analysis: Calcd. (found) (\%) for $\mathrm{C}_{29} \mathrm{H}_{23} \mathrm{~N}_{9} \mathrm{O}_{7} \mathrm{~V}$ : C, 52.73 (52.69); $\mathrm{H}, 3.51$ (3.49); $\mathrm{N}, 19.08$ (19.03). Molar conductivity $\left(\mathrm{CH}_{3} \mathrm{OH}\right)$ : $\lambda_{\mathrm{M}}=215 \Omega^{-1} \mathrm{~cm}^{2} \mathrm{M}^{-1}$. The solid state magnetic moment $\left(\mu_{\mathrm{eff}}\right)$ was found to be 1.78 B.M.

$\alpha$-Glucosidase enzymatic activity: $\alpha$-Glucosidase was used as reported in literature [16]. Rat intestinal acetone powder (Sigma chemicals, USA) was sonicated properly in normal saline $(100: 1 \mathrm{w} / \mathrm{v})$ and after centrifugation at $3000 \mathrm{rpm} \times 30 \mathrm{~min}$ the supernatant was treated as crude intestinal $\alpha$-glucosidase. The release of nitrophenol was read at $405 \mathrm{~nm}$ spectrophotometrically (Multimode ${ }^{\text {synergyH4 }}$ microplate reader, BioTek instrument, Inc. Winoosci, VT, USA). Percent $\alpha$-Glucosidase inhibition was calculated using the following equation:

$$
\alpha \text {-Glucosidase inhibition }(\%)=\left(1-\frac{\mathrm{B}}{\mathrm{A}}\right) \times 100
$$

where A is absorbance of reactants without test samples and $\mathrm{B}$ is absorbance of reactants with test samples.

\section{RESULTS AND DISCUSSION}

The Schiff base (L) was synthesized from the condensation reaction between pyridin-2-yl(pyridin-4-yl)methanone and 2hydrazinopyridine in ethanolic medium (Scheme-I). The Schiff base $\mathbf{L}$ was obtained with sufficient purity and used without further purification in the synthesis of the oxovanadium(IV) complexes 1-4. Reaction of ligand and $\mathrm{VOSO}_{4} \cdot 5 \mathrm{H}_{2} \mathrm{O}$ with polypyridyl ligand in aqueous methanol, afforded pure complexes $[\mathrm{VO}($ phen $)(\mathrm{L})]\left(\mathrm{NO}_{3}\right)_{2}(\mathbf{1})$, [VO(dimphen $\left.)(\mathrm{L})\right]\left(\mathrm{NO}_{3}\right)_{2}$ (2), $[\mathrm{VO}($ bpy $)(\mathrm{L})]\left(\mathrm{NO}_{3}\right)_{2}(3)$ and $\left[\mathrm{VO}(\right.$ bpybenImH) $(\mathrm{L})]\left(\mathrm{NO}_{3}\right)_{2}$ (4), respectively. A aqueous solution of vanadyl sulphate was added to a methanol solution of polypyridyl, followed by the addition of methanol solution of Schiff base with constant stirring for $1 \mathrm{~h}$ to prepare respective vanadyl(IV) complexes 1-4 (Scheme-II). Molar conductivity data $\left(209-215 \Omega^{-1} \mathrm{~cm}^{2}\right.$ 


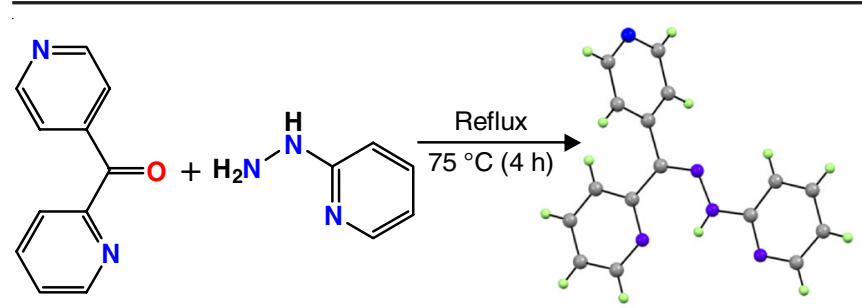

Scheme-I: Syntheses route of Schiff base ligand (L)

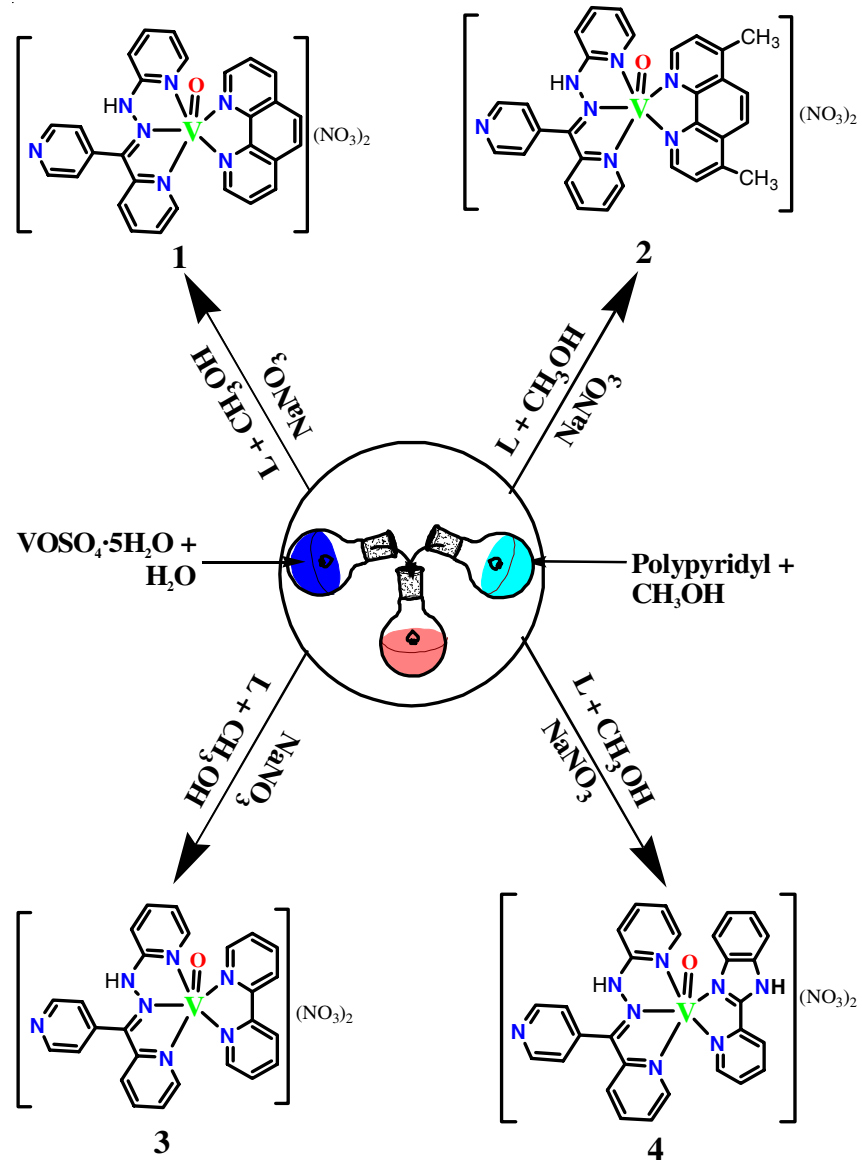

Scheme-II: Syntheses route of oxovanadium(IV) complexes 1-4

$\mathrm{M}^{-1}$ ) revealed the 1:2 ionic nature of all the complexes [17], in accordance with proposed formulations. Magnetic susceptibility measurements for oxovanadium(IV) complexes 1-4 were carried out at room temperature. The room temperature magnetic moments of the complexes 1-4 are in the range 1.74-1.78 B.M. [18]. These data suggested that the complexes are mononuclear and stable in air. All the synthesized oxovanadium(IV) complexes are soluble in DMSO, DMF, ethanol and methanol and insoluble in acetone and diethyl ether.

IR spectral studies: Infrared spectra of Schiff base and its oxovanadium(VI) complexes shows the sharp peaks for formation of azomethine $v_{\text {str }}(>\mathrm{C}=\mathrm{N}-)$ stretching mode at 1635 $\mathrm{cm}^{-1}$. The $\mathrm{N}-\mathrm{H}$ stretching vibration appears as a strong sharp band at $3196 \mathrm{~cm}^{-1}$. Strong bands at $1675 \mathrm{~cm}^{-1}$ for Schiff base and its vanadium complexes can be attributed to $v(\mathrm{C}=\mathrm{N}-\mathrm{N}-\mathrm{C})$ stretching. Additional support in favour of coordination of the azomethine nitrogen atom to vanadium is provide by the shift of $v_{\text {str }}(\mathrm{N}-\mathrm{N})$ bands of the free ligands at $1065-1060 \mathrm{~cm}^{-1}$ to higher frequency region 1093-1091 $\mathrm{cm}^{-1}$ in spectra of all the complexes
[19]. The positive shift of $v_{\text {str }}(\mathrm{N}-\mathrm{N})$ band upon coordination with the vanadium ion may be due to the reduction of repulsion between lone pairs of electrons on the nitrogen atoms. All the vanadium complexes display one sharp band in the 980-930 $\mathrm{cm}^{-1}$ region due to $v(\mathrm{~V}=\mathrm{O})$ mode [12]. The in-plane deformation mode of the pyridine ring $620-520 \mathrm{~cm}^{-1}$ in all the present vanadium complexes, suggests the coordination of pyridine nitrogen [20]. The bands centred at 1445, 1320 and $865 \mathrm{~cm}^{-1}$ exhibited due to the presence of free nitrate ion of all the present vanadium complexes [21]. These findings clearly suggest the coordination of imino nitrogen atoms and pyridine nitrogen atoms donor sites to the vanadium atom and therefore tridentate neutral nature of the coordinated Schiff base (Scheme-I) may be accepted.

Electronic absorption spectral studies: The electronic absorption spectra of synthesized oxovanadium(IV) complexes 1-4 in $\mathrm{CH}_{3} \mathrm{OH}$ show distinct maxima between $360-900 \mathrm{~nm}$ (Fig. 1). The electronic spectra of the complexes (1-4) show two sharp absorption maxima in the range 385 to $405 \mathrm{~nm}$ and $305-515 \mathrm{~nm}$ along with one more broad band unresolved $d-d$ band in the range 745 to $790 \mathrm{~nm}$. The band in the range 385$405 \mathrm{~nm}$ is due to the ligand to metal charge transfer (LMCT) from the pyridine nitrogen to an empty $d$-orbital of vanadium. The $d-d$ band at in the range $745-790 \mathrm{~nm}$ is typical of V(IV) species. Similar three band pattern at about 420,500 and 700 $\mathrm{nm}$ are in agreement with earlier studies [22-24].

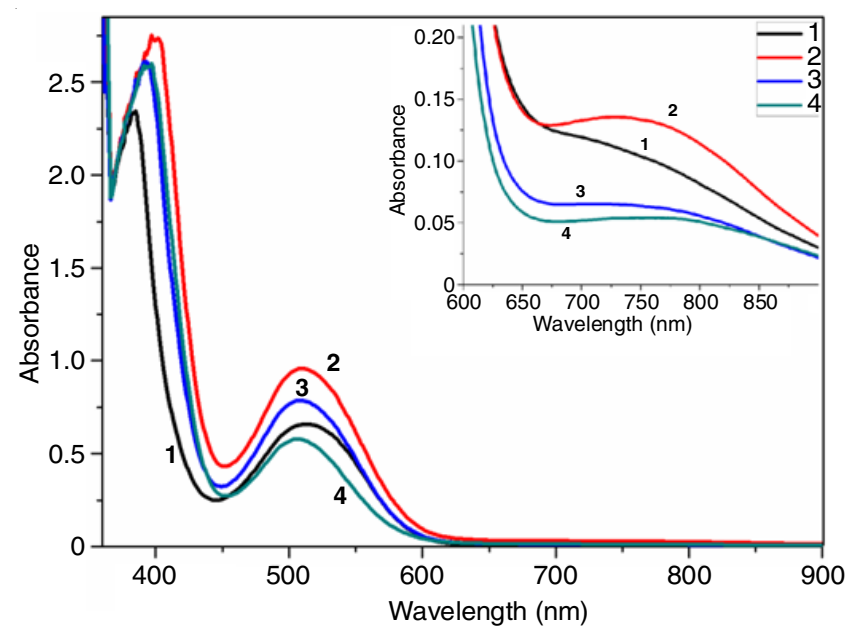

Fig. 1. UV-visible spectra of oxovanadium(IV) complexes

Electrochemistry: The electrochemical behaviours of oxovanadium(IV) complexes 1-4 were assessed in $\mathrm{CH}_{3} \mathrm{OH}$ solution containing $0.1 \mathrm{M}$ TBAP as the supporting electrolyte. Cyclic voltammograms and differential pulse voltammograms were collected in degassed $\mathrm{CH}_{3} \mathrm{OH}$ solution (Fig. 2). The redox behaviours of all synthesized oxovanadium(IV) complexes 1-4 are quite similar. These complexes shows one reduction waves in the range at -0.714 to $-0.816 \mathrm{~V}$ and current potential oxidation wave was not observed. These waves correspond to VO(IV) $\rightarrow \mathrm{VO}(\mathrm{III})$ reduction process. Similar observations were observed using differential pulse voltammertic (DPV) experiment (Fig. 2).

X-band EPR spectral studies: X-band spectra of the complexes 1-4 were recorded at the microwave frequency 9.1 $\mathrm{GHz}$ with TCNE as internal standard in $\mathrm{CH}_{3} \mathrm{OH}$ solution at liquid nitrogen temperature. All the present complexes have 

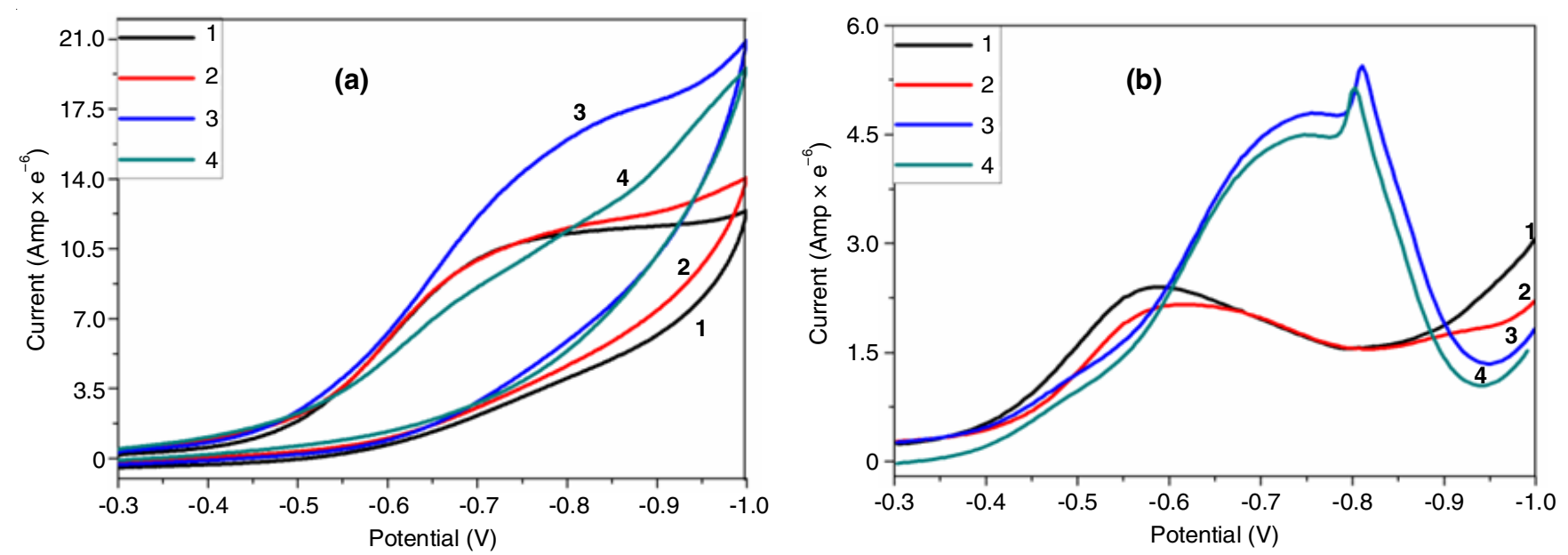

Fig. 2. (a) Cyclic voltammograms of complexes 1-4 in $\mathrm{CH}_{3} \mathrm{OH}$ at an $\mathrm{Ag} / \mathrm{AgCl}$ electrode with an scan rate of $300 \mathrm{mV} \mathrm{s}{ }^{-1}$ (b) Differential pulse voltammograms of complexes 1-4 at room temperature using a scan rate of $20 \mathrm{mV} \mathrm{s}^{-1}$ in $\mathrm{CH}_{3} \mathrm{OH}$. The pulse amplitude is $50 \mathrm{mV}$

shown similar spectral behaviour of representative EPR spectrum of complex 1 is shown in Fig. 3. The nature of all EPR spectra suggests that the all vanadium complexes are paramagnetic. The eight-line hyperfine splitting pattern due to unpaired electron of ${ }^{51} \mathrm{~V}$ nucleus $(I=7 / 2)$ were obtained, indicating that only one mononuclear vanadium(IV) species predominates in all the complexes 1-4. This means that unpaired electron is in the vicinity of $I=7 / 2$ of its own mother nucleus. Thus, the isotropic EPR spectra of a magnetically dilute oxovanadium(IV) complexes gives $2 \times 7 / 2+1=8$ lines. The spin Hamiltonian parameters were calculated and presented in Table-1. Also, the configuration of the complexes 1-4 were assumed to be an axially compared $\mathrm{d}_{\mathrm{xy}}$ pattern: $\mathrm{g}_{\|}<\mathrm{g}_{\perp}$ and $\mathrm{A}_{\|}>\mathrm{A}_{\perp}$ (Table-1). Such observation are agreed with those reported vanadium(IV) complexes [25].

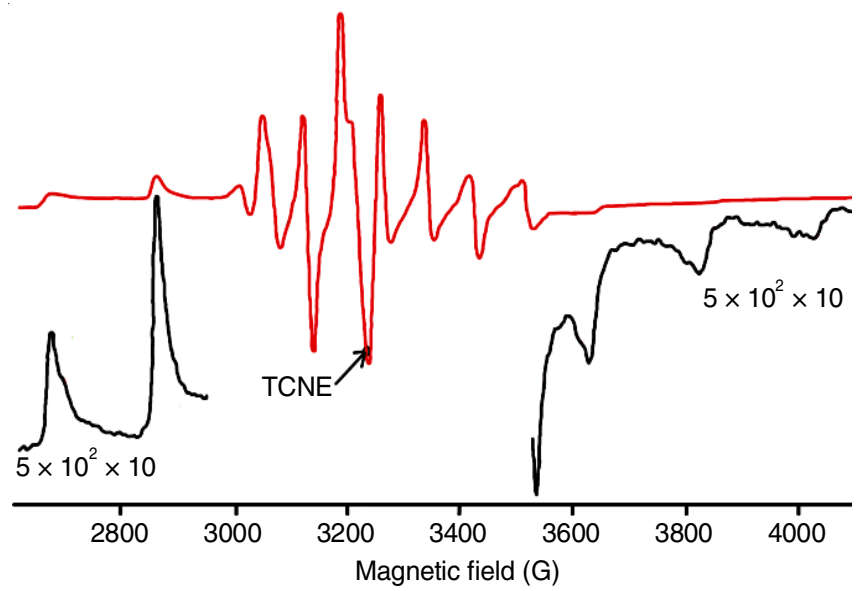

Fig. 3. EPR spectra of complex $\mathbf{1}$

\begin{tabular}{ccccc}
\multicolumn{5}{c}{ TABLE-1 } \\
& $\begin{array}{c}\text { SPIN HAMILTONIAN PARAMETERS OF } \\
\text { VANADIUM(IV) COMPLEXES 1-4 }\end{array}$ \\
\hline Parameter & $\mathbf{1}$ & $\mathbf{2}$ & $\mathbf{3}$ & $\mathbf{4}$ \\
\hline $\mathrm{g}_{\|}$ & 1.928 & 1.935 & 1.915 & 1.931 \\
$\mathrm{~g}_{\perp}$ & 1.975 & 1.962 & 1.927 & 1.972 \\
$\mathrm{~A}_{\|}\left(\mathrm{cm}^{-1}\right)$ & $177.6 \times 10^{-4}$ & $177.3 \times 10^{-4}$ & $176.8 \times 10^{-4}$ & $178.1 \times 10^{-4}$ \\
$\mathrm{~A}_{\perp}\left(\mathrm{cm}^{-1}\right)$ & $68.2 \times 10^{-4}$ & $68.24 \times 10^{-4}$ & $68.7 \times 10^{-4}$ & $68.5 \times 10^{-4}$ \\
\hline
\end{tabular}

$\alpha$-Glucosidase enzymatic activity: Catalytic activity of the complexes 1-4 to mimic the $\alpha$-glucosidase activity was evaluated. The inhibitory effect of the synthesized complexes was evaluated by $\mathrm{IC}_{50}$ value, which shows $50 \%$ inhibition concentration of the complex on $\alpha$-glucosidase. The $\mathrm{IC}_{50}$ values of the complexes are 15.2 for complex $\mathbf{1}, 14.9$ for complex $\mathbf{2}, 15.3$ for complex $\mathbf{3}$ and 15.0 for complex $\mathbf{4}$. These $\mathrm{IC}_{50}$ values are similar to that of reported values of vanadium complexes $[12,13,26,27]$.

\section{Conclusion}

Four new vanadium(IV) complexes were synthesized and characterized with the aim to investigate the in vitro insulin mimetic activity (antidiabetic activity) of complexes. The EPR spectrum of each complexes shows an eight-line pattern $(I=$ $7 / 2$ ), confirming $d^{1} \mathrm{~V}(\mathrm{IV})$ oxidation state. The cyclic voltammetry of oxovanadium(IV) complexes exhibited only on reduction wave, which corresponds to $\mathrm{V}$ (IV) $\rightarrow \mathrm{V}$ (III) reduction process. The in vitro insulin mimetic activity showed that the complexes are better antidiabetic agents.

\section{ACKNOWLEDGEMENTS}

The authors are grateful to RSIC (SAIF) IIT Bombay, Mumbai, India for EPR measurements and SAIF, Central Drug Research Institute, Lucknow, India for micro-analysis.

\section{REFERENCES}

1. D.C. Crans, J.J. Smee, E. Gaidamauskas and L. Yang, Chem. Rev., 104, 849 (2004); https://doi.org/10.1021/cr020607t.

2. M.R. Maurya, A. Kumar, M. Ebel and D. Rehder, Inorg. Chem., 45, 5924 (2006);

https://doi.org/10.1021/ic0604922.

3. Y. Shechter, L. Goldwaser, M. Mironchik, M. Fridkin and D. Gefel, Coord. Chem. Rev., 237, 3 (2003);

https://doi.org/10.1016/S0010-8545(02)00302-8.

4. G.Y. Yeh, D.M. Eisenberg, T.J. Kaptchuk and R.S. Phillips, Diabetes Care, 26, 1277 (2003); https://doi.org/10.2337/diacare.26.4.1277.

5. B. Song, N. Aebischer and C. Orvig, Inorg. Chem., 41, 1357 (2002); https://doi.org/10.1021/ic0111684.

6. D. Rehder, Biometals, 5, 3 (1992); https://doi.org/10.1007/BF01079691.

7. U. Schollowock, J. Richter, D.J.J. Farnell and R.F. Bishop, Quantum Magnetism, Springer-Verlage, New York (2004). 
8. V.G. Yuen, P. Caravan, L. Gelmini, N. Glover, J.H. McNeill, I.A. Setyawati, Y. Zhou and C. Orvig, J. Inorg. Biochem., 68, 109 (1997); https://doi.org/10.1016/S0162-0134(97)00082-2.

9. H. Sakurai, K. Fujii, H. Watanabe and H. Tamura, Biochem. Biophys. Res. Commun., 214, 1095 (1995); https://doi.org/10.1006/bbrc.1995.2398.

10. J. Leiter, J.L. Hartwell, J.S. Kahler, I. Kline and M.J. Shear, J. Natl. Cancer Inst., 14, 365 (1953); https://doi.org/10.1093/jnci/14.2.365.

11. C. Krishnamurty, L.A. Byran and D.H. Petering, Cancer Res., 40, 4092 (1980).

12. R.N. Patel and Y.P. Singh, J. Mol. Struct., 1153, 162 (2018); https://doi.org/10.1016/j.molstruc.2017.10.010.

13. R.N. Patel and Y.P. Singh, Asian J. Chem., 29, 2327 (2017); https://doi.org/10.14233/ajchem.2017.20921.

14. R.N. Patel, Y.P. Singh, Y. Singh, R.J. Butcher and J.P. Jasinski, Polyhedron, 133, 102 (2017); https://doi.org/10.1016/i.poly.2017.05.028.

15. Y.P. Singh, R.N. Patel, Y. Singh, D. Choquesillo-Lazarte and R.J. Butcher, Dalton Trans., 46, 2803 (2017); https://doi.org/10.1039/C6DT04661D.

16. S. Mishra, K.B. Pandeya, A.K. Tiwari, A.Z. Ali and T. Saradamani, J. Indian Chem. Soc., 88, 1195 (2011).

17. W.J. Geary, Coord. Chem. Rev., 7, 81 (1971); https://doi.org/10.1016/S0010-8545(00)80009-0.

18. S.K. Dutta, E.R.T. Tiekink and M. Chaudhury, Polyhedron, 16, 1863 (1997);

https://doi.org/10.1016/S0277-5387(96)00491-3.
19. M. Akbar Ali, A.H. Mirza, C.W. Voo, A.L. Tan and P.V. Bernhardt, Polyhedron, 22, 3433 (2003); https://doi.org/10.1016/j.poly.2003.08.004.

20. A.P. Rebolledo, M. Vieites, D. Gambino, O.E. Piro, E.E. Castellano, C.L. Zani, E.M. Souza-Fagundes, L.R. Teixeira, A.A. Batista and H. Beraldo, J. Inorg. Biochem., 99, 698 (2005); https://doi.org/10.1016/j.jinorgbio.2004.11.022.

21. Y.P. Singh, R.N. Patel, Y. Singh, R.J. Butcher, P.K. Vishakarma and R.K.B. Singh, Polyhedron, 122, 1 (2017); https://doi.org/10.1016/j.poly.2016.11.013.

22. S.B. Etcheverry, E.G. Ferrer, L. Naso, J. Rivadeneira, V. Salinas and P.A.M. Williams, J. Biol. Inorg. Chem., 13, 435 (2008); https://doi.org/10.1007/s00775-007-0332-9.

23. P.A.M. Williams, S.B. Etcheverry and E.J. Baran, Carbohydr. Res., 329, 41 (2000); https://doi.org/10.1016/S0008-6215(00)00171-3.

24. S.B. Etcheverry, D.A. Barrio, P.A.M. Williams and E.J. Baran, Biol. Trace Elem. Res., 84, 227 (2001); https://doi.org/10.1385/BTER:84:1-3:227.

25. A. Sreedhara, C.P. Rao and B.J. Rao, Carbohydr. Res., 289, 39 (1996); https://doi.org/10.1016/0008-6215(96)00100-0.

26. R.N. Patel, K. Maurya, Y.P. Singh, Y. Singh, S. Rather, A. Kamal and I.P. Tripathi, J. Indian Chem. Soc., 94, 347 (2017).

27. S. Mishra, K.B. Pandeya, A.K. Tiwari, A.Z. Ali, T. Saradamani, S.B. Agawane and K. Madhusudana, Int. J. Nutr. Metab., 4, 11 (2012). 